\title{
SUMBER DAYA DALAM MENGIMPLEMENTASI PROGRAM ADIWIYATA DI SMK NEGERI 1 NGASEM
}

\author{
Asifatul Umroh \\ Seruni Endahsari \\ Mufarrihul Hazin \\ STAIN Kediri, Indonesia \\ asifatulumroh@gmail.com
}

\begin{abstract}
One of the causes of environmental damage is caused by human activities that are not aware of the importance of the environment. Therefore, the government seeks to provide awareness through the application of environmental education in the form of Adiwiyata. This study aims to determine how the resources in implementing the Adiwiyata program at SMK Negeri $1 \mathrm{Ngasem}$. The method used is a qualitative approach to the type of case study research. This research was conducted at SMK Negeri $1 \mathrm{Ngasem}$, Kediri. Data collection used is observation, interview and documentation, analysis used is condensation, data presentation and conclusion drawing. The validity of the data uses triangulas and peers. The results of this study indicate that, Adiwiyata's policy at SMK Negeri 1 Ngasem is "Clean Friday", where every month on the second week is Friday, before starting teaching and learning activities all school members conduct cleaning activities in the school environment for 45 minutes. In addition there is also a policy "Free of Pollution" ie every student is not allowed to park in the school environment both motorized vehicles and bicycles, except parking for Principals, Teachers, employees and also for guests who visit SMK Negeri 1 Ngasem there is a separate parking space in the school environment. And resources that support the implementation of the Adiwiyata program at SMK Negeri 1 Ngasem, there are 4 main types of resources, which include first, human resources. In improving human resources both teachers, staff, and components in the school. Second, financial resources (funds or budget). Funds or budget used to implement the Adiwiyata program use funds from the school treasury. Third, facility resources. Since the school was established and officially inaugurated the Adiwiyata program, facilities and infrastructure that support the implementation of the Adiwiyata program. For example the formation of PLS extracurricular, KIR, Adiwiyata room, etc. Fourth, information resources. This school provides information on environmental education insight by means of teacher meetings, announcements during ceremonies and outreach to the surrounding community.
\end{abstract}

Keywords: Adiwiyata, Implementation of the program

\begin{abstract}
Abstrak: Penyebab salah satu kerusakan lingkungan hidup terjadi karena ulah manusia yang kurang sadar akan pentingnya lingkungan. Oleh karena itu, pemerintah berupaya memberikan penyadaran melalui penerapan pendidikan lingkungan hidup dalam bentuk Adiwiyata. Penelitian ini bertujuan untuk mengetahui bagaimana sumber daya dalam mengimplementasikan program Adiwiyata di SMK Negeri $1 \mathrm{Ngasem}$. Metode yang digunakan adalah pendekatan kualitatif dengan jenis penelitian studi kasus. Penelitian ini dilakukan di SMK Negeri 1 Ngasem, Kediri. Pengumpulan data yang digunakan yaitu observasi, wawancara dan dokumentasi, analisis yang digunakan yaitu kondensasi, penyajian data dan penarikan kesimpulan. Keabsahan data menggunakan triangulas dan teman sejawat. Hasil penelitian ini menunjukkan bahwa, kebijakan Adiwiyata di SMK Negeri 1 Ngasem yaitu "Jumat Bersih", dimana setiap bulan pada minggu ke dua yaitu hari jumat, sebelum mulai kegiatan belajar mengajar semua warga sekolah melakukan kegiatan bersih-bersih di lingkungan sekolah selama 45 menit. Selain itu ada juga kebijakan "Bebas Polusi" yaitu setiap siswa tidak diperkenankan parkir di lingkungan sekolah baik kendaraan bermotor maupun sepeda, terkecuali parkir untuk Kepsek, Guru, karyawan dan juga untuk tamu yang berkunjung di SMK Negeri 1 Ngasem ada tempat parkir tersendiri di lingkungan sekolah. Dan Sumber daya yang mendukung implementasi program Adiwiyata di SMK Negeri $1 \mathrm{Ngasem}$ terdapat 4 jenis sumber daya utama, yaitu meliputi pertama, sumber daya manusia. Dalam meningkatkan sumber daya manusia baik guru, staff, dan komponen
\end{abstract}


yang ada di sekolah. Kedua, sumber daya finansial (dana atau aggaran). Dana atau anggaran yang digunakan untuk melaksanakan program Adiwiyata menggunakan dana dari kas sekolah. Ketiga, sumber daya fasilitas. Sejak sekolah ini didirikan dan diresmikan menjalankan program Adiwiyata, fasilitas sarana dan prasarana yang menunjang terlaksananya program Adiwiyata. Misalnya dibentuknya ekstrakulikuler PLS, KIR, ruang Adiwiyata, dll. Keempat, sumber daya informasi. Sekolah ini dalam memberikan informasi tentang wawasan pendidikan lingkungan hidup dengan cara rapat guru, pengumuman saat upacara dan sosialisasi ke lingkungan masyarakat sekitar.

\section{Kata Kunci: Adiwiyata, Implementasi program}

Pendidikan di Indonesia merupakan salah satu prioritas utama yang dilakukan oleh pemerintah. Hal tersebut telah dijelaskan dalam Pembukaan Undang-Undang Dasar 1945. Sebab untuk menjadikan negara yang maju maka dibutuhkan sumber daya manusia yang berkualitas dengan mengedepankan system pendidikannya. Pendidikan memiliki berbagai manfaat, salah satunya adalah mendukung kegiatan penyelamatan bumi dan pengelohan lingkungan. Pemerintah Indonesia membuat suatu kebijakan yang diterapkan dalam dunia pendidikan yang tertera dalam pasal 65 poin keempat Undang-Undang Nomor 32 Tahun 2009 tentang Perlindungan dan Pengelolaan Lingkungan Hidup. Di mana dalam pasal tersebut menjelaskan bahwa "setiap orang berhak dan berperan dalam pengelolaan lingkungan hidup". Dari pernyataan tersebut pemerintah dalam hal ini adalah institusi pendidikan dimaksudkan ikut serta dalam melaksanakan pengelolaan lingkungan melalui perencanangan program sekolah Adiwiyata.

Adiwiyata menurut (Susy, 2011) sebagai "tempat yang baik dan ideal dimana dapat diperoleh segala ilmu pengetahuan dan berbagai norma serta etika yang dapat menjadi dasar manusia menuju terciptanya kesejahteraan hidup kita dan menuju kepada cita-cita pembangunan berkelanjutan". (Depdiknas, 2002), menyatakan bahwa lingkungan hidup adalah "kesatuan ruang dengan semua benda, daya, keadaan, dan makhluk hidup, termasuk manusia dan perilakunya yang mempengaruhi perikehidupan dan kesejahteraan manusia dan makhluk hidup lainnya". Adiwiyata atau lingkungan hidup merupakan suatu ruang atau tempat yang ideal dan strategis, karena di dalamnya terjadi interaksi secara kondusif untuk mencapai kehidupan yang lebih baik.

Program Adiwiyata yaitu sebuah program yang bertujuan untuk menciptakan kondisi yang baik bagi sekolah untuk manjadi tempat pembelajaran dan penyadaran warga sekolah, untuk mendorong upaya penyelamatan lingkungan dan pembangunan berkelanjutan (sustainable development) yang pada akhirnya dapat mewujudkan kelembagaan sekolah yang peduli dan berbudaya lingkungan berdasarkan norma, kebersamaan, keterbukaan, kejujuran, keadilan, dan kelestarian hidup dan sumber daya alam (Ilham, 2011)

Tujuan program adiwiyata menurut (Susy, 2011) adalah "mewujudkan warga sekolah yang bertanggung jawab dalam upaya perlindungan dan pengelolaan lingkungan hidup melalui tata kelola sekolah yang baik untuk mendukung pembangunan yang berkelanjutan".

Menciptakan lingkungan kondusif menjadi tanggung jawab semua elemen yang ada di sekolah tersebut. Adapun yang ada di sekolah adalah kepala sekolah, guru, pegawai tata usaha, dan pegawai lainnya. Semuanya bertanggung jawab mewujudkan lingkungan yang kondusif.

(Susy, 2011) menyatakan bahwa pelaksanaan program adiwiyata diletakkan pada dua prinsip dasar yaitu "prinsip partisipatif dan berkelanjutan". Prinsip partisipatif artinya komunitas sekolah terlibat dalam manajemen sekolah yang meliputi keseluruhan proses perencanaan, pelaksanaan dan evaluasi sesuai tanggungjawab dan peran. Prinsip berkelanjutan artinya bahwa seluruh kegiatan harus dilakukan secara terencana dan terus menerus secara komprehensif. 
Pelaksanaan program sekolah Adiwiyata berawal pada tahun 2007. Diawali kerjasama antara Badan Lingkungan Hidup dan Dinas Pendidikan Kabupaten Kediri memberikan penyuluhan atau sosialisasi kepada sekolah-sekolah yang ada di Kediri mengenai program Adiwiyata baik sekolah negeri maupun swasta. SMK Negeri 1 Ngasem Kabupaten Kediri mengikuti program sekolah Adiwiyata sejak tahun 2009 dan diresmikan pada tahun 2011, untuk tingkat kabupaten pada tahun 2013 dan untuk tingkat provinsi jatim pada tahun 2014 dan tingkat nasional pada tahun 2015. Pada tahun 2016 sekolah mengajukan sebagai sekolah adiwiyata mandiri akan tetapi masih ada kendala dari pembina $\mathrm{LH}$ hubungannya dengan SK.

Udoji yang dikutip oleh (Solichin, 2005) mendefinisikan kebijakan publik sebagai suatu tindakan bersanksi yang mengarah pada suatu tujuan tertentu yang diarahkan pada suatu masalah atau sekelompok masalah tertentu yang berkaitan satu sama lain yang mampu mempengaruhi sebagain besar warga. Untuk menyederhanakan dalam implementasi kebijakan, maka dibentuk model-model implementasi kebijakan.Model-model implementasi kebijakan tersebut akan memudahkan dalam pelaksanaan proses kebijakan. Pada penelitian ini peneliti menggunakan model implementasi (Edward III dalam (Widodo, 2010)) yang di dalamnya terdapat empat faktor yang mempengaruhi keberhasilan dan kegagalan dalam implementasi kebijakan. Empat factor atau variable tersebut adalah factor komunikasi, sumber daya, disposisi, dan struktur birokrasi. (Cory, 2017). Namun titik tumpu terberat kami dalam penelian ini adalah pada segi factor sumber daya karena untuk mencapai tujuan implementasi kebijakan secara efektif dan efisien, maka memperhatikan ketentuan atau aturan yang ada. Jika pelaku kebijakan tidak memperhatikan sumber daya, yang di dapat implementasi kebijakan tersebut akan berjalan tidak efektif dan efisien. Faktor sumber daya dalam model implementasi kebijakan menurut Edward III dibagi menjadi empat. Yang pertama sumber daya manusia yang berpengaruh terhadap pelaksanaan kebijakan. Sumber daya dalam model ini harus cukup (jumlah) dan cakap (keahlian). Sumber daya manusia harus ada ketepatan dan kelayakan antara jumlah staff (sumber daya manusia) yang dibutuhkan dan keahlian yang dimiliki sesuai dengan tugas pekerjaan yang ditanganinya. Yang kedua adalahs umber daya keuangan atau anggaran, yang mana berpengaruh terhadap efektivitas pelaksanaan kebijakan. Apabila terjadi keterbatasan dana dan peralatan, yang terjadi adalah kurang optimalnya pelaksanaan kebijakan. Banyak permasalahan baik dalam tubuh organisasi maupun program yang akan dilaksanakan. Sehingga dibutuhkan sistem akuntabilitas dalam melaksanakan implementasi kebijakan.Yang ketiga, sumber daya peralatan yang mana sebagai sarana untuk operasional dalam pelaksanaan kebijakan yang meliputi gedung, tanah dan sarana yang semuanya akan memudahkan saat memberikan pelayanan dalam implementasi kebijakan. Dengan terbatasnya fasilitas yang tersedia, kurang menunjang efisiensi dan tidak mendorong motivasi para pelaku dalam melaksanakan kebijakan. Yang keempat ialah sumber daya informasi dan kewenangan. Kewenangan merupakan sumberdaya lain yang mempengaruhi efektivitas pelaksanaan kebijakan. Kewenangan sangat diperlukan, terutama untuk menjamin dan meyakinkan bahwa kebijakan sanaan yang akan dilaksanakan adalah sesuai dengan yang mereka kehendaki.

Adiwiyata merupakan sebuah program sekolah yang bagus untuk diimplementasikan di sekolah. fasilitas dan gedung sekolah adiwiyata menciptakan lingkungan yang kondusif untuk belajar serta dapat menghemat energi,sumber daya dan uang.(Zhang, Zhang, \& Zheng, 2014) selain itu, program adiwiyata juga mempengaruhi kurikulum dan kegiatan yang ada di sekolah.(Technica, 2012)

Penelitian sebelumnya menunjukkan data saat ini siswa sudah memiliki kesadaran terhadap program adiwiyata di sekolah.(Hafiffah, Abdul, Iksan, Zarina, \& Zakaria, 2003). Sehingga empat aspek dari program adiwiyata perlu diimplementasikan dengan prinsip-prinsip 
edukatif, partisipatif

dan berkelanjutan.(Fadlilah \& Ngabekti, 2018)

Siswa memiliki peran dan kontribusi yang penting dalam implementasi program adiwiyata di sekolah, persepsi siswa adiwiyata penting bagi mereka serta penting untuk kelangsungan hidup manusia. (Bowosantoso, 2015). Guru juga berperan dalam implementasi adiwiyata di sekolah, guru sepenuhnya menerapkan pengalaman belajar dengan memanfaatkan fasilitas hijau disekolah sebagai laboratorium pembelajaran. (Kerlin, Santos, \& Bennett, 2015)

Pemimpin atau kepala sekolah juga berperan penting dalam implementasi adiwiyata di sekolah, kepala sekolah membutuhkan pengembangan professional dalam mengakses dan menggunakan informasi teknologi untuk berlatih pengajaran dan pemodelan berkelanjutan.(Kensler, 2013)

\section{METODE}

Jenis penelitian yang digunakan dalam penelitian ini adalah jenis penelitian kualitatif dengan jenis studi kasus. Penelitian ini berusaha mendapatkan informasi yang selengkap mungkin mengenai sumber daya dalam mengimplementasikan program adiwaiyata di SMK Negeri 1 Ngasem. Penelitian Kualitatif (Cresswell, 2010) "peneliti membuat suatu gambaran kompleks, meneliti kata-kata, laporan terinci dari pandangan responden, dan melakukan studi pada situasi yang alami”. Data kualitatif diungkapkan dalam bentuk kalimat serta uraian-uraian dari pihak-pihak yang terlibat dalam pelaksanaan program Adiwiyata di SMK Negeri 1 Ngasem.

Lokasi penelitian ini dilakukan di SMK Negeri 1 Ngasem Kabupaten Kediri. Data yang berdasarkan sumber pengambilannya dalam penelitian ini berasal dari dua sumber, yakni primer dan skunder. Pengumpulan data dilakukan melalui wawancara, observasi dan dokumentasi. Instrumen penelitian ada peneliti sendiri, pedoman wawancara dan catatan lapangan. Penelitian ini menggunakan analisis data dengan model interaktif menurut Miles dan Huberman yang dikutip oleh (Sugiyono, 2012) yaitu melalui tahap reduksi data atau kondesasi, penyajian data, dan penarikan kesimpulan. Keabsahan data yang digunakan yaitu dengan triangulasi dan teman sejawat.(Miles \& Huberman, 1994)

\section{HASIL}

Hasil penelitian yang dipaparkan merupakan hasil analisis dan validasi dan sudah merupakan hasil proses kondensasi dari sekolah yang menjadi objek penelitian. Dimana dalam pembahasan ini akan membahas dua hal yaitu, kebijakan Adiwiyata dan implementasi kebijakan Adiwiyata disekolah yang menjadi objek penelitian.

a. Kebijakan Adiwiyata

SMK Negeri 1 Ngasem sebagai sekolah Adiwiyata telah memiliki dan mengembangkan kebijakan sekolah yang berwawasan Lingkungan Hidup, yaitu Visi, Misi dan Tujuan sekolah yang tertuang dalam kurikulum sekolah sudah memuat kebijakan Lingkungan Hidup. Visi, Misi dan Tujuan ini sudah diketahui dan dimengerti oleh semua warga sekolah.

Sekolah Adiwiyata adalah sekolah yang peduli dan berbudaya lingkungan dimana program Adiwiyata adalah program untuk mewujudkan sekolah peduli dan berbudaya lingkungan yang diselenggarakan oleh menteri lingkungan hidup dan menteri pendidikan (Permen No.05 Tahun 2013).

Tujuan Adiwiyata adalah mewujudkan warga sekolah yang bertanggung jawab dalam upaya perlindungan dan pengelolaan lingkungan hidup melalui tata kelola sekolah yang baik untuk mendukung pembangunan yang berkelanjutan (Susy, 2011).

Dari pembahasan tersebut dapat disimpulkan bahwa program Adiwiyata adalah suatu program yang diselenggarakan oleh menteri lingkungan hidup dan menteri pendidikan dengan tujuan mendorong warga sekolah untuk peduli akan lingkungan hidup, yang di dalamnya 
memuat indikator-indikator yang dapat menunjang tercapainya tujuan program Adiwiyata. Seperti SMK Negeri 1 Ngasem memiliki kebijakan agar tercapai tujuan program Adiwiyata, yaitu dengan kebijakan "Jumat Bersih". Dimana setiap bulan pada minggu ke dua yaitu hari jumat, sebelum mulai kegiatan belajar mengajar semua warga sekolah melakukan kegiatan bersihbersih di lingkungan sekolah selama 45 menit.

Selain itu SMK Negeri 1 Ngasem juga memiliki kebijakan "Bebas Polusi" yaitu setiap siswa tidak diperkenankan parkir di lingkungan sekolah baik kendaraan bermotor maupun sepeda, terkecuali parkir untuk Kepsek, Guru, karyawan dan juga untuk tamu yang berkunjung di SMK Negeri 1 Ngasem ada tempat parkir tersendiri di lingkungan sekolah.

\section{b. Implementasi Kebijakan Adiwiyata}

Pengertian implementasi sejalan dengan pengertian pelaksanaan yang dikemukakan oleh (Pidarta, 2011) bahwa "pelaksanaan adalah aktifitas menjalankan perencanaan yang sudah ditetapkan sebelumnya".

Program sekolah Adiwiyata merupakan bentuk komitmen pemerintah terhadap pengelolaan dan perlindungan lingkungan melalui pendidikan. kebijakan yang dibuat oleh pemerintah yaitu melalui (Hidup, 2013) Peraturan Menteri Lingkungan Hidup Nomor 5 Tahun 2013 diterjemahkan menjadi program Adiwiyata. Implementasi program tersebut di SMK Negeri 1 Ngasem mendapat Sertifikat Nomor 660.1/3003/418.69/2013 dalam Sekolah Adiwiyata Tingkat Kabupaten dari Pemerintah Kabupaten Kediri.

Hasil penelitian menunjukkan bahwa SMK Negeri 1 Ngasem tedapat faktor sumber daya dalam mengimplementasikan program Adiwiyata.

Hal ini sesuai dengan (Fryde, 2018) Edwards III sumber daya (resources) yang dimaksud dalam implementasi kebijakan adalah pelaksanaan kebijakan. Agar dapat dilaksanakan dengan baik, kesiapan sumber daya pelaksana, ketersediaan informasi yang memadai, kewenangan yang diberikan kepada pelaksana kebijakan serta ketersediaan sarana dan prasarana penunjang dalam pelaksanaan kebijakan.

Sumber daya yang mendukung implementasi program Adiwiyata di SMK Negeri 1 Ngasem terdapat 4 jenis sumber daya utama, yaitu meliputi pertama, sumber daya manusia. Dalam meningkatkan sumber daya manusia baik guru, staff, dan komponen yang ada di sekolah. Di sekolah ini selalu menerapkan pola kerjasama yang baik diantaranya dengan membagi tugas program kerja (POKJA) antara guru dan siswa, serta tanggung jawab bersama. Dengan adanya pola tanggung jawab warga sekolah ikut serta dalam menjalankan Visi, Misi dan Tujuan Sekolah berwawasan Lingkungan Hidup.

Kedua, sumber daya finansial (dana atau aggaran). Dana atau anggaran yang digunakan untuk melaksanakan program Adiwiyata menggunakan dana dari kas sekolah dan bantuan dari Siswa berupa tempat sampah, rak sepatu, dan tanaman hias. Untuk dana atau anggaran yang digunakan ekstra PLS (Pendidikan Lingkungan Sekolah) yaitu dari dana hasil pengumpulan kertas bekas dan uang kas dari anggota PLS.

Ketiga, sumber daya fasilitas. Sejak sekolah ini didirikan dan diresmikan menjalankan program Adiwiyata, fasilitas sarana dan prasarana yang menunjang terlaksananya program Adiwiyata. Misalnya sekarang sudah dibentuknya ekstrakurikuler yang berkaitan dengan lingkungan hidup yaitu PLS (Pendidikan Lingkungan Sekolah) dan KIR (Karya Ilmiah Remaja), ruangan Adiwiyata, taman anggrek, Green House, taman sekolah, hutan sekolah, alat pendaur ulang, dll. Dan disekolah tersebut juga tersedia kantin bebas 5P yaitu pengawet, pewarna, pemanis, penyedap dan plastik karena plastik salah satu sampah yang sulit diuraikan. Selain itu melalui ektrakulikuler KIR siswa-siswi SMK Negeri 1 Ngasem mengembangkan bakatnya dengan 
menerapkan daur ulang, misalnya membuat kerajinan baju yang terbuat dari kain bekas dan klobot plastik, kemudian vas bunga yang terbuat dari koran dan sedotan bekas.

Keempat, sumber daya informasi. Sekolah ini dalam memberikan informasi tentang wawasan pendidikan lingkungan hidup dengan cara rapat guru, pengumuman saat upacara dan sosialisasi ke lingkungan masyarakat sekitar yang berada di dekat sekolah serta juga melakukan kunjungan ke sekolah lainya yang berada di kabupaten kediri untuk diberi pembinaan mengenai pelaksanaan program Adiwiyata.

\section{KESIMPULAN}

Dari hasil pembahasan dapat ditarik kesimpulan bahwa SMK Negeri 1 Ngasem memiliki kebijakan "Jumat Bersih" yang dilaksanakan setiap 1 bulan sekali di minggu kedua, dimana semua warga sekolah melakukan kegiatan bersih-bersih selama 45 menit. Kebijakan "Bebas Polusi", semua siswa tidak diperkenankan untuk parkir di dalam sekolah kecuali Kepsek, Guru, Karyawan dan tamu sekolah. Dimana semua kebijakan itu diharapkan dapat menunjang keberhasilan tujuan program Adiwiyata.

Dalam mengimplementasikan program tersebut SMK Negeri $1 \mathrm{Ngasem}$ mendapat Sertifikat Nomor 660.1/3003/418.69/2013 dalam Sekolah Adiwiyata Tingkat Kabupaten dari Pemerintah Kabupaten Kediri serta terdapat 4 sumber daya utama yang mendukung dalam mengimplementasi program Adiwiyata, diantaranya pertama sumber daya manusia, kedua sumber daya finansial (dana atau anggaran), ketiga sumber daya fasilitas, dan keempat sumber daya informasi.

\section{DAFTAR RUJUKAN}

Bowosantoso, J. T. (2015). Green School in the Perspective of Secondary

School Students in Semarang , Central Java. 5(6), 34-42. https://doi.org/10.9790/738805633442
Cory. (2017). Policy Implementation of International Undergraduate Program In Indonesia's Higher Education System: A Study at Faculty of Economics and Business University of Brawijaya. RJOAS, 6(June), 199-204.

Cresswell, J. W. (2010). Research design (Pendekatan kualitatif, kuantitatif dan mixed). Yogyakarta: Pustaka Pelajar.

Depdiknas. (2002). Kamus Besar Bahasa Indonesia. Jakarta: Balai Bahasa.

Fadlilah, U., \& Ngabekti, S. (2018). Journal of Innovative Science Education The Adiwiyata School's Role in the Development of Character Caring for the Environment ( A Case Study at the Junior High School 6 Tuban ). 7(1), 53-61.

Fryde, E. B. (2018). Financial Resources of Edward III in the Netherlands, 133740 ( 2nd part ). 40, 1142-1216.

Hafiffah, N., Abdul, B., Iksan, Z. H., Zarina, S., \& Zakaria, S. (2003). Students' reflection on green school. 44-52.

Hidup, K. Li. Pedoman Pelaksanaan Program Adiwiyata. , (2013).

Ilham. (2011). Buku Profil Adiwiyata di Surabaya. Surabaya.

Kensler, L. A. W. (2013). An elicitation study using the Theory of Planned Behavior. 4(January).

Kerlin, S., Santos, R., \& Bennett, W. (2015). Green Schools as Learning Laboratories? Teachers' Perceptions of Their First Year in a New Green Middle School « Journal of Sustainability Education. Journal of Sustainability Education, 8(January). Retrieved from http://www.jsedimensions.org/wordpre ss/content/green-schools-as-learninglaboratories-teachers-perceptions-oftheir-first-year-in-a-new-green-middleschool-2_2015_01/

Miles, M. B., \& Huberman, a M. (1994). Qualitative Data Analysis: A Sourcebook. Sage Publications, Beverly Hills, California USA, 19(1), 1-263. https://doi.org/10.1016/01497189(96)88232-2 
Ritza Nurindah', Andi Nurochmah, Ibnu Hurri, Pengaruh Multimedia Terhadap Motivasi Dan Hasil Belajar

Pidarta, M. (2011). Manajemen pendidikan Indonesia. BAndung: Rineka Cipta.

Solichin, A. W. (2005). Analisis Kebijaksanaan: Dari Formulasi ke Implementasi Kebijaksanaan Negara (Kedua). Jakarta: Bumi Aksara.

Sugiyono. (2012). Metode Penelitian Kuantitatif Kualitatifdan R\&D. Bandung: Alfabeta.

Susy, H. S. (2011). Panduan Adiwiyata. Jakarta.

Technica, G. (2012). Implementation Of Environmental Education Case Study: Activating The " Green School "Program Among Elementary School Students In Israel. (2), 52-58.

Widodo, J. (2010). Analisis Kebijakan Publik. Malang: Bayumedia Publishing.

Zhang, J., Zhang, Z., \& Zheng, Y. (2014). An Introduction of Building Green Schools. Journal of Sustainable Development, 2(1).

https://doi.org/10.5539/jsd.v2n1p200 